\title{
Pancreatico-portal Dissociation: A Canine Model to Evaluate the Hepatic Maintenance Effects of Partial Portal Flow Diversion and Pancreatic Hormone Deprivation ${ }^{1}$
}

\author{
F. E. Eckhauser, M.D., J. A. Knol, M.D., W. A. Arneson, M.D., \\ and Charles G. Child, III, M.D. \\ Surgical Research Laboratories, Ann Arbor Veteran's Hospital, and Department of Surgery, \\ University of Michigan Medical Center, Ann Arbor, Michigan 48109 \\ Submitted for publication June 20, 1978

\begin{abstract}
Pancreatico-portal dissociation provides a viable canine experimental model for evaluating the effects of portal flow reduction and pancreatic hormone deprivation in liver mainenance. Initial studies indicate flow as a "vehicle" for substrate (and/or hormone) delivery and imply a possible contribution to hepatic maintenance of the gastrosplenic venous axis.
\end{abstract}

\section{INTRODUCTION}

One hundred years has passed since Nicolai Eck first described the technical feasibility of diverting all portal blood into the inferior vena cava by his now world famous Eck fistula. The physiologic effects of this operation upon hepatic function and regeneration were than unknown. As years have passed, however, investigators have learned that hepatic function and regeneration are impaired, but the reasons for this are not yet fully understood. Some [2-4] believe that the basic defect is one of blood flow while others, "the humoralists" [5-7], have stressed the primacy of hepatotrophic factors in portal blood. Numerous animal models, including portocaval transposition [3], partial or split portocaval transportation [8], splanchnic division [10], arterialization [11], and parabiotic cross-circulation [12], have evolved in order to test the relationship(s) and relative importance of these components. The present work was undertaken to create an experimental model which would reduce overall portal venous flow and dissociate the pancreato-duodenal and gastrosplenic venous axes (pancreatico-portal dissociation).

\footnotetext{
1 This research was supported by RAAGS and by Michigan Heart Foundation Grant 341095.
}

\section{MATERIALS AND METHODS}

A total of 32 conditioned female mongrels weighing from $16-30 \mathrm{~kg}$ body wt, divided into a normal control group $(n=15)$ and an experimental group $(n=17)$ were used. Following a 24-hr fast, anesthesia was induced in all dogs with intravenous Surital (Thiamylal; Parke-Davis) and maintained with methoxyflurane. Intravenous crystalloid solutions were administered intraoperatively and no antibiotics were provided. An arterial cannula placed in a femoral artery branch was used to measure pre- and intraoperative blood pressure and blood gases. All flow measurements were taken under stable conditions with a mean arterial blood pressure of $100-120 \mathrm{~mm} \mathrm{Hg}$.

All dogs had recovered sufficiently within $24 \mathrm{hr}$ of operation to resume preoperative diets of standard canned meat chow supplemented ad lib with dry chow. Preoperative and weekly postoperative assessments were made of body weight, liver function tests, standard hemograms, and clinical status. Interval studies ( 5 weeks to 7 months) of shunt patency and mesenterico-portal recollaterization were performed using ${ }^{99 \mathrm{~m}} \mathrm{Tc}$ labeled albumin microspheres. ${ }^{2}$

$2{ }^{99 m}$ Tc-labeling achieved a specific activity of $1 \mathrm{mCi} / \mathrm{ml}$ with a free Tc level of $<1 \%$. Ninety-five per- 


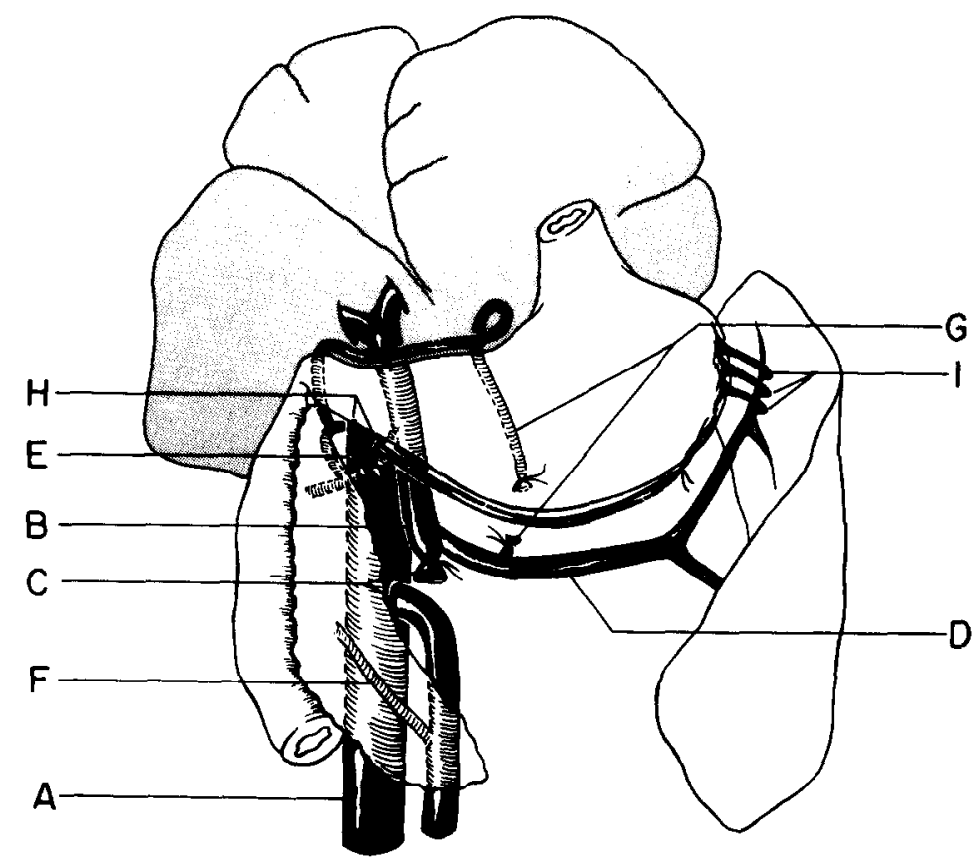

FIG. 1. Pancreato-portal dissociation model: (A) inferior vena cava, (B) portal vein, (C) divided mesenteric vein with meso-caval anastamosis, (D) splenic vein, (E) superior pancreato-duodenal vein, (F) inferior pancreato-duodenal vein, (G) divided coronary vein, $(\mathrm{H})$ divided right gastro epiploic bundle, (I) short gastric veins.

Of the 17 experimental animals, 9 were sacrificed at 6 weeks and the remaining 7 at 5-7 months. At sacrifice, flows were remeasured and following microsphere injection into a mesenteric venous radicle, total hepatectomy was performed. Wet liver weight (minus gallbladder weight) was determined and comparative radionuclide concentration studies were performed on liver and abdominal wall samples, the latter as an index for background tissue concentration. Microsphere data were compared between dissociation and control groups. All results were compared using Student's $t$ test for independent samples. Light microscopy was performed on all liver samples using hematoxylin-eosin, Masson's tri-

cent of the labeled particles were $10-45 \mu \mathrm{m}$ in size and $<2 \%$ were smaller than $10 \mu \mathrm{m}$. A dose of $100 \mu \mathrm{Ci}$ containing $9000 \pm 300$ particles was assayed in its syringe prior to injection. Tissue concentrations $(\mathrm{cpm} / \mathrm{g}$ ) were assayed in a Chicago Nuclear well-type scintillation counter. chrome, and PAS stains. Glycogen content was qualitatively assessed in each section.

\section{DESCRIPTION OF OPERATION ${ }^{3}$}

All operations were performed using a long midline incision. The portal vein was dissected free exposing its major tributaries, the splenic and mesenteric veins. The superior pancreato-duodenal vein was ligated

${ }^{3}$ As nearly as we can determine the vascular rearrangements in this operation have been described twice in the past. First, Arthur H. Blakemore described it many years ago when he and Dr. Whipple were evolving applicable methods of portal decompression in addition to Eck fistulas and spleno renal shunts. Dr. Blakemore believed this operation might have some usefulness in treating patients with portal hypertension. The operation was never used in the laboratory and only rarely in man. In any event, after devising it, $\mathrm{Dr}$. Blakemore discarded it [13]. Second, Dr. Mazzoni and Dr. Di Martino described it in a brief report to the Tripartite Meeting for Surgical Research held in Philadelphia in 1976. This article was, to the best of our knowledge, never published [14]. 
TABLE 1

Changes in Liver Weight as a Percentage of Body Weight following Pancreato-portal Dissociation

\begin{tabular}{cccc}
\hline & $\begin{array}{c}\text { Normals } \\
(n=15)\end{array}$ & $\begin{array}{c}\text { Acutc dissociations } \\
(6 \text { weeks }) \\
(n=9)\end{array}$ & $\begin{array}{c}\text { Chronic dissociations } \\
(6 \text { months }) \\
(n=6)\end{array}$ \\
\hline LW/BW $(\bar{x} \% \pm \mathrm{SE})$ & $2.6 \pm 0.1^{*}$ & $2.1 \pm 0.1$ & $1.9 \pm 0.2$ \\
\hline
\end{tabular}

* Acute vs normal, $P<0.02$; chronic vs normal, $P<0.01$; acute vs chronic, NS.

and divided after which the infrahepatic inferior vena cava was mobilized. The splenic vein was skeletonized by dividing all pancreatic tributaries as well as the coronary vein and a $50 \%$ pancreatectomy was performed leaving the head and uncinate lobe. The mesenteric vein was divided at its confluence with the splenic vein, and an end-to-side anastamosis between the mesenteric vein and the vena cava was accomplished using a continuous 6-0 Prolene suture. Finally, the caudal aspect of the pyloric region was skeletonized, dividing the right gastro-epiploic vascular bundle (Figure 1).

Flows were measured preshunt, postshunt, and at sacrifice (Carolina Electronics Square Wave Electromagnetic flow meter) in the common hepatic artery, portal vein, and infrahepatic inferior vena cava.

\section{RESULTS}

Of the nine animals in the acute group (sacrifice at 6 weeks), all survived surgery and seven of nine (78\%) survived to sacrifice. One dog died in the first postoperative day with a bowel infarction resulting from prolonged intraoperative mesenteric vein occlusion and another died of unknown causes on the fifth postoperative day. All surviving dogs remained alert and demonstrated no clinical evidence of inanition or "'meat intoxication." Of eight animals in the chronic group (sacrifice at 5-7 months) early operative mortality was zero and of the six of cight (75\%) surviving, all were indistinguishable clinically from the acute group. One late fatality was due to fighting and the other from unknown causes.
Hematologic abnormalities were transient, consisting of early significant elevation in WBC, SGOT, SGPT, and alkaline phosphatase $(P<0.01)$ and depression of serum levels of total protein and albumin. By the fifth postoperative week all values had returned to normal ranges $(P>0.2)$.

Postoperative weight loss was maximal at 1 week with nearly all animals achieving their preoperative weights by the second week and maintaining them until sacrifice. Liver weights obtained at sacrifice tended to reductions from expected $(2.6 \% \mathrm{TBW})^{4}$ and were statistically significant $(P<0.01$ and $P<0.02)$ in both chronic and acute groups. Liver weight loss as a percentage of total body weight was greater in the chronic group (Table 1).

Normal values and subsequent alterations in hepatic blood flow were standardized in terms of liver weight ( $\mathrm{ml} \mathrm{blood} \mathrm{flow} / \mathrm{min} /$ $100 \mathrm{~g}$ liver wt), and compared to controls. Decreases in total hepatic and portal venous blood flow were statistically significant ( $P$ $<0.05$ and $P<0.01$ respectively) as were compensatory increases in common hepatic arterial flow $(P<0.01)$ (Table 2$)$.

The ${ }^{99 m}$ Tc-labeled albumin microsphere studies demonstrated a significant differential hepatic trapping in normals as compared to both acute and chronic dissociation groups $(P<0.01$ and $P<0.01)$. Differential liver/abdominal wall muscle trapping in acute versus chronic groups was not statistically significant $(P>0.2)$ (Table 3$)$.

\footnotetext{
${ }^{4}$ Liver weight as a percentage of total body weight calculated in this laboratory by weighing resected livers in 15 normal dogs.
} 
TABLE 2

Hepatic Blood Flow Alterations following Pancreato-portal Dissociationa

\begin{tabular}{lcc}
\hline & $\begin{array}{c}\text { Normals } \\
(n=15)\end{array}$ & $\begin{array}{c}\text { Acute dissociations } \\
(6 \text { weeks }) \\
(n=7)\end{array}$ \\
\hline Total hepatic blood flow & $166.5 \pm 14.8$ & $105.5 \pm 7.1^{* *}$ \\
Portal vein blood flow & $148.5 \pm 14.3$ & $70.7 \pm 5.3^{*}$ \\
Common hepatic artery flow & $18.0 \pm 1.6$ & $34.7 \pm 3.2^{*}$ \\
\hline
\end{tabular}

${ }^{a}$ In milliliters per minute per $100 \mathrm{~g}$ liver weight.

$* \bar{x} \pm \mathrm{SE}, P<0.01$.

** $P<0.05$.

\section{DISCUSSION}

Maintenance of normal hepatic function is reported to be largely flow dependent $[3$, 17]. Partial or total portal diversion results hemodynamically in an incomplete compensatory increase in hepatic arterial flow [18, 19], presumably by decreasing terminal hepatic arteriolar (or sinusoidal) transmural pressure [20]. However, the net result is a reduction in overall hepatic blood flow. Our data demonstrate that partial portal diversion results in 36.6 and $52.4 \%$ reductions in $\mathrm{THBF}^{5}$ and PVBF respectively and a $93 \%$ increase in HABF. The compensatory increase in HABF $(18.0$ to $35 \mathrm{ml} / \mathrm{min} / 100 \mathrm{~g}$ liver weight) was quantitatively less than the reduction in portal vein flow (167 to 105 $\mathrm{ml} / \mathrm{min} / 100 \mathrm{~g}$ liver weight), an observation cited by previous investigators $[15,16]$.

The observed $25 \%$ increase in comparison to other values (THBF and PVFB) is explainable in terms of an increase in the mesenteric circulation secondary to hypercapnia. Respiratory depression $\left(\mathrm{p}\left(\mathrm{CO}_{2}\right) 52 \pm 8 \mathrm{~mm} \mathrm{Hg}\right)$ was repeatedly noted when anesthetic levels necessary to obtain abdominal wall relaxation were achieved. Previous investigators have demonstrated hypercapnia-induced increases in mesenteric and hepatic blood flow by measuring increases in portal venous pressure unassociated with concomitant increases in hepatic resistance $[23,24]$. These

\footnotetext{
${ }^{5}$ THBF, total hepatic blood flow; PVBF, portal venous blood flow; HABF, hepatic arterial blood flow.
}

conditions were duplicated throughout the experiment to maintain uniformity of results.

Several investigators have shown the utility of radioactive microspheres in determining regional blood flow [25-27]. Hepatic arterial flows of $34-41 \mathrm{ml} / \mathrm{min} / 100 \mathrm{~g}$ liver and skeletal muscle flows of $22-29 \mathrm{ml} / \mathrm{min} / 100 \mathrm{~g}$ muscle (a ratio of $1.35-1.50: 1$ ) have been described. Completeness of portal dissociation and the absence of mesenterico-portal collaterals in our model was documented by liver-skeletal muscle ratios of 1.0-1.28. Microsphere injection into a mesenteric venous radicle normally yields a high liverskeletal muscle isotope concentration ratio due to complete liver trapping. With complete dissociation of mesenteric flow, as in our model, liver radioactivity can only be attributed to small particles capable of passing through the pulmonary capillary bed $(<7 \mu \mathrm{m})$ or to free ${ }^{99 \mathrm{~m}} \mathrm{Tc0}_{4}{ }^{-}$. Since hepatic arterial and skeletal muscle flows are comparable [25-27], the activity ratio of liver/ muscle should approach unity on a weight basis when mesenteric flow is successfully diverted, and did so in our model. The lack at sacrifice of clinically apparent mesentericoportal collaterals and mesenteric venous hypertension further substantiated completeness of dissociation.

The canine model of pancreatico-portal dissociation (modified Eck fistula) is well tolerated as evidenced by normal body weights, normal basic liver function tests, and good general clinical condition. A peri- 
operative mortality rate of $12 \%(2.17)$ and an extended survival at 5-7 months of $77 \%$ (13/17) was achieved.

Despite the apparent good health of all surviving animals, the fall in ratio of liver weight to total body weight was statistically significant and suggests some measure of hepatic atrophy in the dissociated group. Histologic evaluation failed to show any significant qualitative morphological differences between the two groups. Although biochemical tests of subtle hepatocellular dysfunction (e.g., bromsulphthalein extraction or ammonium chloride extraction) were not utilized, the normalcy of standard liver function tests in the dissociated group is consistent with the observed minimal hepatic atrophy.

The absence of severe hepatic atrophy induced by partial portal flow deprivation and systemic diversion of pancreatic "hepatotrophic" factors is explicable in the following ways: (i) overall quantitative delivery to the liver of pancreatic (and other) hepatotrophic factors may be relatively unaltered if complete pancreatico-mesenteric blood flow diversion results in elevated circulating systemic plasma levels of such portal hepatotrophic factors as insulin, glucagon, or pancreatic polypeptide, and (ii) gastro-splenic venous blood may qualitatively contribute to liver maintenance. This study suggests a model which may be used to study these relationships. No attempt was made to delineate them specifically.

The hepatic maintenance role of the gastro-splenic component of portal venous blood flow has to date remained uninvestigated. The importance of portal blood flow per se $[4,5,12,17]$ and of humoral factors found in pancreatico-duodenal and intestinal venous effluents $[7-10]$ is undeniable, but the role(s) of each remain unclear. This preparation provides a model to more specifically determine if the hepatic atrophy observed incident to total porto-systemic diversion $[2,7,10-12]$ occurs secondary to reduced total hepatic "hepatotrophic" factor delivery and to investigate the possible
TABLE 3

Comparative Liver/Muscle ${ }^{99 m}$ Tc Microsphere activity Ratio following Pancreato-portal Dissociation

\begin{tabular}{ccc}
\hline $\begin{array}{c}\text { Normals } \\
(n=5)\end{array}$ & $\begin{array}{c}\text { Acute } \\
\text { dissociations } \\
(n=7)\end{array}$ & $\begin{array}{c}\text { Chronic } \\
\text { dissociations } \\
(n=6)\end{array}$ \\
\hline $\begin{array}{c}261 \pm 92^{*} \\
(\bar{x} \pm \mathrm{SE})\end{array}$ & $1.00 \pm 0.2$ & $1.28 \pm 0.3$ \\
\hline
\end{tabular}

* Acute vs normal, $P<0.01$; chronic vs normal, $P<0.01 ;$ acute vs chronic, NS.

qualitative role of the spleen in liver maintenance.

\section{ACKNOWLEDGMENTS}

The authors wish to acknowledge the technical contributions of Vicki Porter-Fink, Revius Williams, Larry Starks, and Dennis Lockrey. Their help was invaluable in developing this canine experimental model. ${ }^{99 \mathrm{~m} T \mathrm{~T}}$ microspheres courtesy of $3 \mathrm{M}$ Company (Minneapolis, Minn.).

\section{REFERENCES}

1. Eck, N. V. Ligature of the portal vein. Voen. Med. J. 130(2): 1, 1877. (Translated and discussed by Child, C. G. Eck's fistula. Surg. Gynecol. Obstet. 96: 375, 1953).

2. Mann, F. C. Restoration and pathologic reactions of the liver. J. Mt. Sinai Hosp. New York 11: 65, 1944.

3. Child, C. G., Barr, D., Holswade, G. R., et al. Liver regeneration following portocaval transposition in dogs. Ann. Surg. 138: 600, 1953.

4. Fisher, B., Russ, C., et al. Effect of increased hepatic blood flow upon liver regeneration. Arch. Surg. 69: 263, 1954.

5. Starzl, T. E., Marchioro, T. L., et al. Immunosuppression after experimental and clinical homotransplantation of the liver. Ann. Surg. 160: 411, 1964.

6. Fisher, B., Szuch, P., and Fisher, E. Evaluation of a humoral factor in liver regeneration utilizing liver transplants. Cancer Res. 31: 322, 1971.

7. Starzl, T. E., Porter, K. A., et al. Portal hepatotrophic factors, diabetes mellitus and acute liver atrophy, hypertrophy and regeneration. Surg. Gynecol. Obstet. 141(6): 843, 1975.

8. Marchioro, T. L., Porter, K. A., et al. The specific influence of nonhepatic splanchnic venous blood flow upon the liver. Surg. Forum. 16: 280, 1969.

9. Chandler, J. G., Lee, S., et al. The roles of interliver competition and portal blood in regeneration of auxiliary liver transplants. Surg. Forum 22: 341, 1971. 
10. Starzl, T. E., Francarilla, A., et al. The origin, hormonal nature and action of portal venous hepatotrophic factors. Surg. Gynecol. Obstet. 137; 179, 1973.

11. Fisher, B., Russ, C., and Bluestone, C. Composition of the regenerated dog liver following partial hepatectomy and total arterialization. Amer. J. Physiol. 181: 203, 1955.

12. Fisher, B., Lee, S., et al. Liver regeneration following portocaval shunt. Surgery 52(1): 88, 1962.

13. Vorhees, A. B., Jr. Personal communication, 1978.

14. Mazzoni, G., and Di Martino, C. The Hepatotrophic Effects of the Spleen on the Hepatic Regeneration. Presented at The Third Tripartite Meeting of the Society of University Surgeons, The Surgical Reseach Society, The European Society for Experimental Surgery, Philadelphia, Pa., Sept. 27-29, 1976.

15. Selkurt, E. Comparison of the bromsulphalein method with simultaneous direct hepatic blood flow. Circ. Res, 2: 155, 1954.

16. Drapanas, T., Kluge, D. N., and Schenk, W. G. Measurement of hepatic blood flow by bromsulphalein and by electromagnetic flow meter. Surgery 48: 1017, 1960.

17. Wexler, M., McDermott, W., et al. Regeneration and maintenance of integrity of canine liver. Arch. Surg. 101: 267, 1970.

18. Ackrnyd, F. W., and McDermott, W. Autonomic vasomotor controls in hepatic blood flow. Amer. $J$. Surg. 112: 356, 1966.
19. Cohn, R., and Kounts, S. Factors influencing control of arterial circulation in the liver of the $\mathrm{dog}$. Amer. J. Physiol. 205: 1260, 1963.

20. Hanson, K. M., and Johnson, P. C. Local control of hepatic arterial and portal venous flow in the dog. Amer. J. Physiol. 211: 712, 1966.

21. Fischer, A. Dynamics of the circulation in the liver. In C. Rouiller, (Ed.), The Liver, Morphology, Biochemistry and Physiology, New York: Academic Press, 1963. Vol. 1, pp. 329-378.

22. Radinovici, N., and Vardi, J. The intrahepatic portal vein hepatic artery relationship. Surg. Gynecol. Obstet. 120: 38, 1965.

23. Brickner, E., and Dowds, E. Mesenteric blood flow as influenced by progressive hypercapnia. Amer. J. Physiol. 184: 275, 1955.

24. Mohamed, M. S., and Bean, J. W. Local and general alterations of blood $\mathrm{CO}_{2}$ and influence of intestinal motility in regulation of intestinal blood flow. Amer. J. Physiol. 167: 413, 1951.

25. Nuetze, J., Wyler, F., and Rudolph, A. Changes in distribution of cardiac output after hemorrhage in rabbits. Amer. J. Physiol. 215(4): 857, 1968.

26. Forsythe, R. P., Nies, A. S., Wyler, F., et al. Normal distribution of cardiac output in the unanesthetized, restrained rhesus monkey. I. Appl. Physiol. 25(6): 736, 1968.

27. Forsythe, R. P., Nies, A. S., Wyler, F., et al. Redistribution of cardiac output during hemorrhage in the unanesthetized monkey. Circ. Res. 27: 311, 1970. 